\title{
A Numerical Study of the Terrain Effects on a Squall Line
}

\author{
Ching-Sen Chen \\ Institute of Atmospheric Physics \\ National Central University, Chung-Li, Taiwan, R.O.C.
}

(Received 27 March 1990; revised 4, May 1990)

\begin{abstract}
Observations indicate that some squall line systems moving from the Taiwan Strait towards the mountains would decrease in intensity and dissipate. Obviously the terrain effects on the squall lines are very important. A two-dimensional terrain following coordinated cloud model was used to study geographical effects on a squall line. In the model the mountain peak was assumed to be 1 or $2 \mathrm{~km}$ in height with the squall line forming over the plain area and propagating towards the mountains. In the plain area new convection continually formed on the forward side of the squall line so that the squall line could maintain itself. When the squall line moved over mountainous areas it slowed down and began decreasing its intensity due to the weakness of new convection. The decrease in intensity resulted from less moisture flowing into the squall line at the higher altitude. The terrain effect on the restriction of the development of the squall line was more evident the higher the mountain.
\end{abstract}

\section{INTRODUCTION}

The effects of mountainous terrain on precipitation systems have been discussed very extensively in the past (Smith, 1979). Recently Yoshizaki and Ogura (1988) demonstrated that orographic lifting could induce heavy precipitation in a moisture-rich low-level flow environment. In Taiwan the mountain ranges go north-south-ward and are very lofty, and they can inhibit the development of some precipitation systems propagating eastward from the Taiwan Strait towards the mountains. During TAMEX (Taiwan Area Mesoscale Experiment) a north-south orientated squall line system moved from the strait toward Taiwan island in the late evening of May 16, 1987. It dissipated in the mountainous area the next morning (Cunning, 1988). Another squall line affected by mountains occurred on May 2, 1989. It did some damage in SW Taiwan but decayed when it reached the mountainous area (Chen Wang and Lin, personal 
communication). Naturally the question arises as to why the intensity of these squall lines decreased in mountainous areas.

For this paper we artificially formed a squall line using a two-dimensional cloud model in the environment based on a sounding observed at Makung during TAMEX on May 16, 1987. This model squall line was propagated towards the mountains. Investigation of the evolution of the squall line in these mountainous areas will enable us to have better understanding of the influence of terrain on a squall line. This TAMEX case was chosen for use here because Dopplar data were collected for a squall line occurring near mountainous areas. We may thus be able to compare our model result about the topographical effect on the squall line to that in the Doppler analysis after the analysis is finished.

\section{THE NUMERICAL MODEL AND INITIAL FIELDS}

In order to study the effect of a north-south orientated mountain on a northsouth orientated squall line a two-dimensional cloud model was designed. This model was derived from a two-dimensional version of a three-dimensional convective cloud model from Klemp and Wilhelmson (1978). Some modifications have been made: a terrain-following coordinate system was introduced; a waveabsorbing layer was added to the top of the domain; a turbulent mixing parameterization depending on the relative strengths of stratification and shear (Lilly, 1962) was used. The equations used in our two- dimensional model are shown in the Appendix, however a more detailed description of the model is shown in Durran and Klemp (1982).

The terrain structure used in this study is shown in Fig. 1 and the following equation:

$$
z_{s}(x)=\frac{h a^{2}}{x^{2}+a^{2}}
$$

$h$ is the mountain peak and $a$ is $2400 m$ or $144000 m$ depending on the $x$ on the west or the east side of the mountain peak, respectively. On the east side of the mountain the altitude decreases more gently than on the west side. This terrain shape is intended to represent the high mountain area on the east part of the domain.

The base of the domain $(z=0)$ and the pressure there are assumed to be $0 \mathrm{~m}$ and $1000 \mathrm{hPa}$, respectively. A warm rain micro- physical parameterization of Kessler (1969) is used, where water is divided into three forms: water vapor, cloud water, and rain. The grid size in the $x$-direction is constant and is taken to be $1 \mathrm{~km}$, where it is stretched in the vertical to allow finer resolution in the lower atmosphere. There are 361 and 22 grid points in the horizontal and vertical directions, respectively. The model domain is $360 \mathrm{~km}$ by $18.2 \mathrm{~km}$. The location of the horizontal velocity $u$, vertical velocity $w$, non-dimentional 

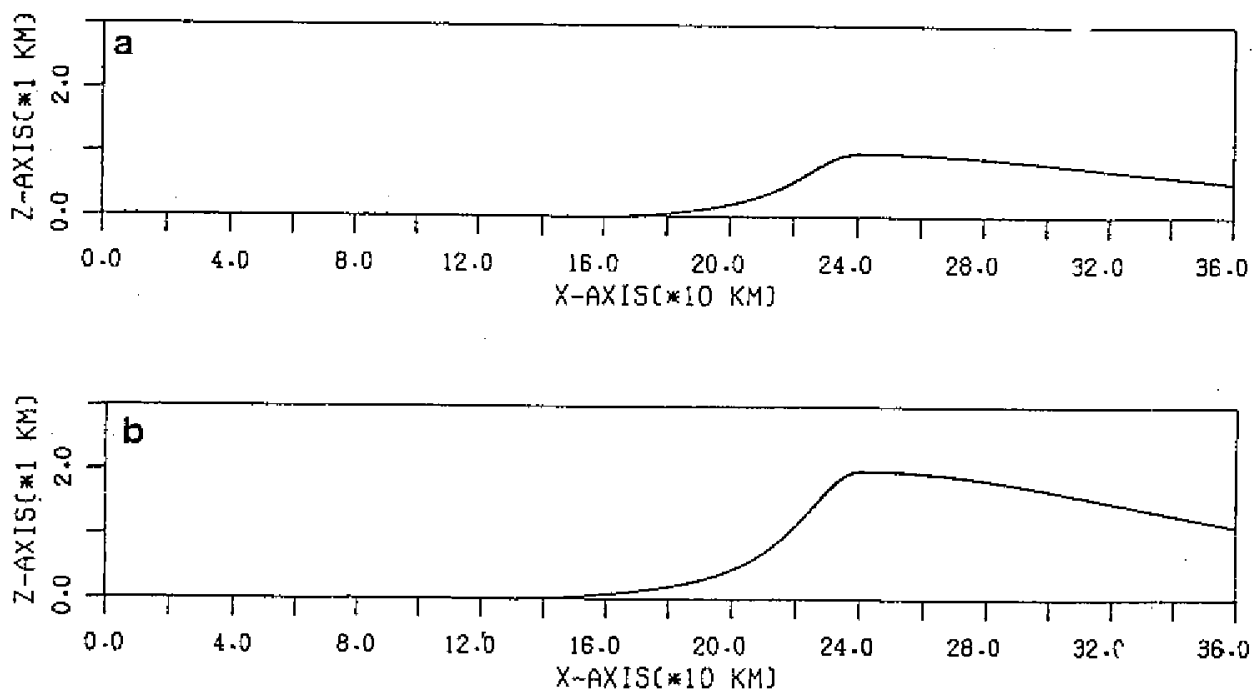

Fig. 1. The terrain features used in run $A$ and $B$ (a) and run $C$ (b).

pressure perturbation $\pi^{\prime}$, potential temperature $\theta$, subgrid scale mixing for momentum $K_{h}$ and scalar $K_{m}$, the mixing ratio of water vapor $Q_{v}$, cloud water $Q_{c}$ and rain $Q_{r}$ in the vertical direction $z$ are shown in Table 1. Their location in the vertical direction $\eta$ for the terrain following coordinate system is calculated by

$$
\eta=\frac{z_{t}\left(z-z_{s}\right)}{z_{t}-z_{s}}
$$

where $z_{t}$ is the top of the domain $18.2 \mathrm{~km}$.

Table 1. The location of variables in the $z$ direction. Vertical velocity is located at ZRW position and all other variables are located at ZRT position.

\begin{tabular}{|c|c||c|c|}
\hline ZRT $(\mathrm{m})$ & ZRW $(\mathrm{m})$ & ZRT $(\mathrm{m})$ & ZRW $(\mathrm{m})$ \\
\hline 18175 & 18200 & 5240 & 4833 \\
16684 & 17422 & 4442 & 4067 \\
15257 & 15963 & 3707 & 3363 \\
13892 & 14566 & 3035 & 2722 \\
12590 & 13233 & 2425 & 2144 \\
11351 & 11963 & 1879 & 1630 \\
10175 & 10755 & 1396 & 1178 \\
9062 & 9611 & 975 & 789 \\
8012 & 8529 & 618 & 463 \\
7025 & 7511 & 324 & 200 \\
6101 & 6555 & 92 & 0 \\
\hline
\end{tabular}

Absorbing layers are assumed on the top of the model and are about $11 \mathrm{~km}$ 
thick. Rayleigh damping has been used as in Durran and Klemp (1982).

The initial temperature and moisture conditions for this simulation were based on the sounding taken at Makung at 14 LST on May 16, 1987. It was relatively moist in the troposphere except near $700 \mathrm{hPa}$ (Fig. 2 ). Based on the temperature and moisture profiles the profiles of potential temperature $\theta$, equivalent potential temperature $\theta_{e}$, and saturated equivalent potential temperature $\theta_{e}^{*}$ are presented in Fig. 2b. It was potentially and conditionally unstable below $80 \mathrm{hPa}$. If an air parcel was lifted from $950 \mathrm{hPa}$ it would acquire a temperature excess beginning at $850 \mathrm{hPa}(\approx 1.5 \mathrm{~km})$, the height where its $\theta_{\mathrm{e}}$ would exceed the environmental $\theta_{e}^{*}$. However if an air parcel was lifted above $900 h P a$ it would not easily gain positive buoyant energy with respect to environmental $\theta_{e}^{*}$.

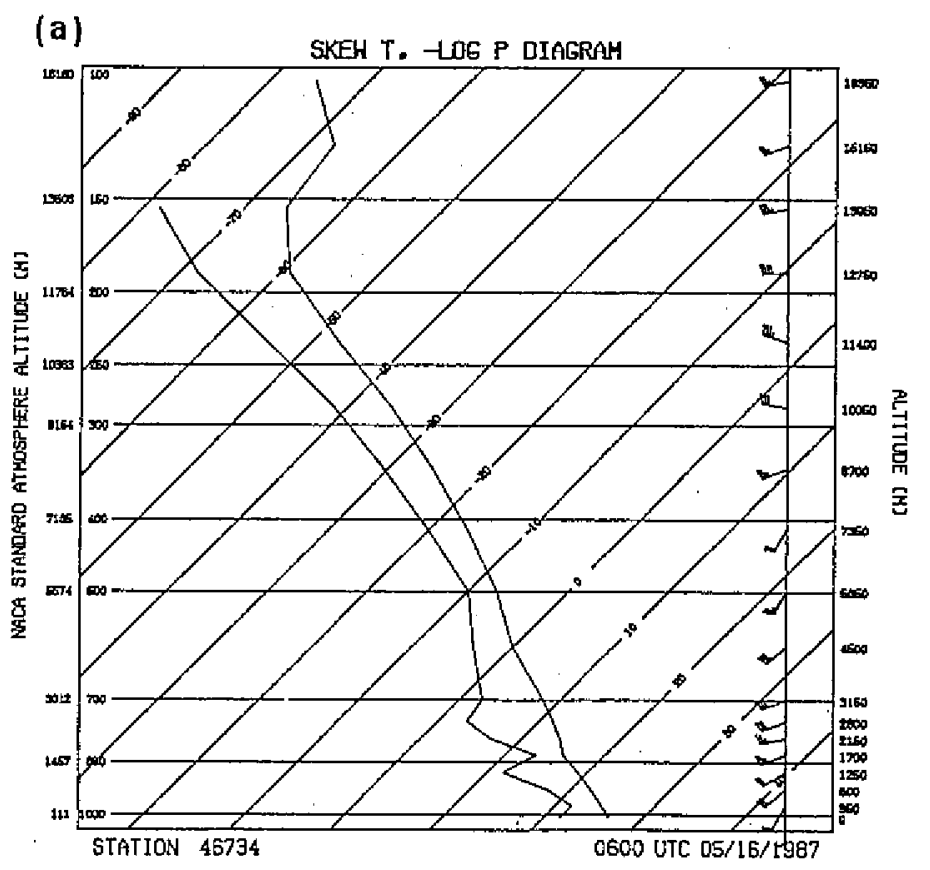

Fig. 2. (a). Initial sounding used in the model simulation taken at Makung at 14 LST, May 16, 1987.

Initially the observed east-west wind component was assigned everywhere in the model above the mountain top. Below the mountain peak wind was gradually increasing over an hour from zero to the observed value of the sounding. Meanwhile all the progonostic variables were integrated forward except cloud and rain. Then we let the model adjust itself by integrating forward without considering any microphysical process for another $11 / 2$ hours. 


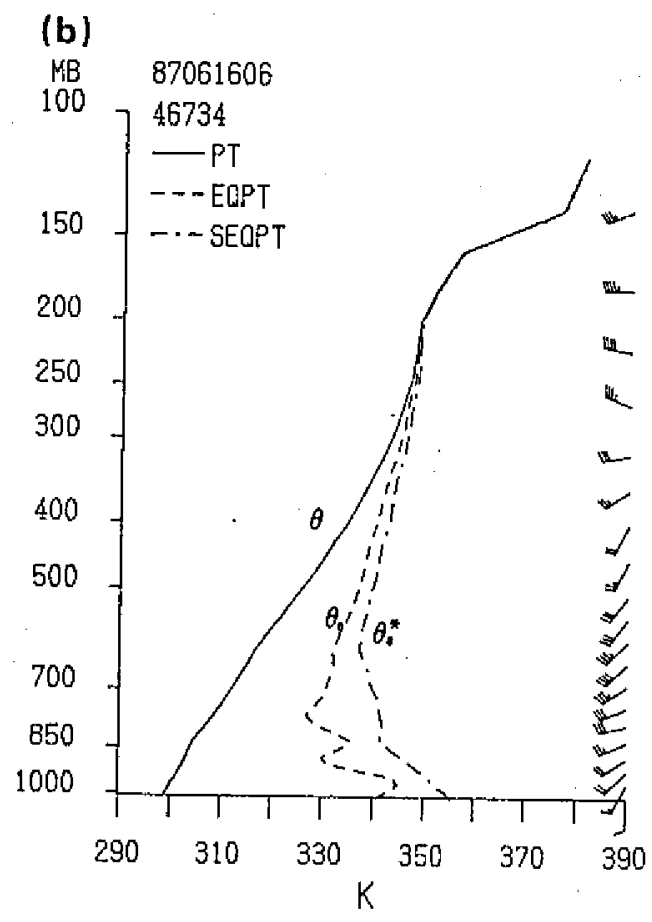

Fig. 2. (b). The profiles of potential temperature $\theta$, equivalent potential temperature $\theta_{e}$, and saturated equivalent potential temperature $\theta_{e}^{*}$ derived from Fig. 2a.

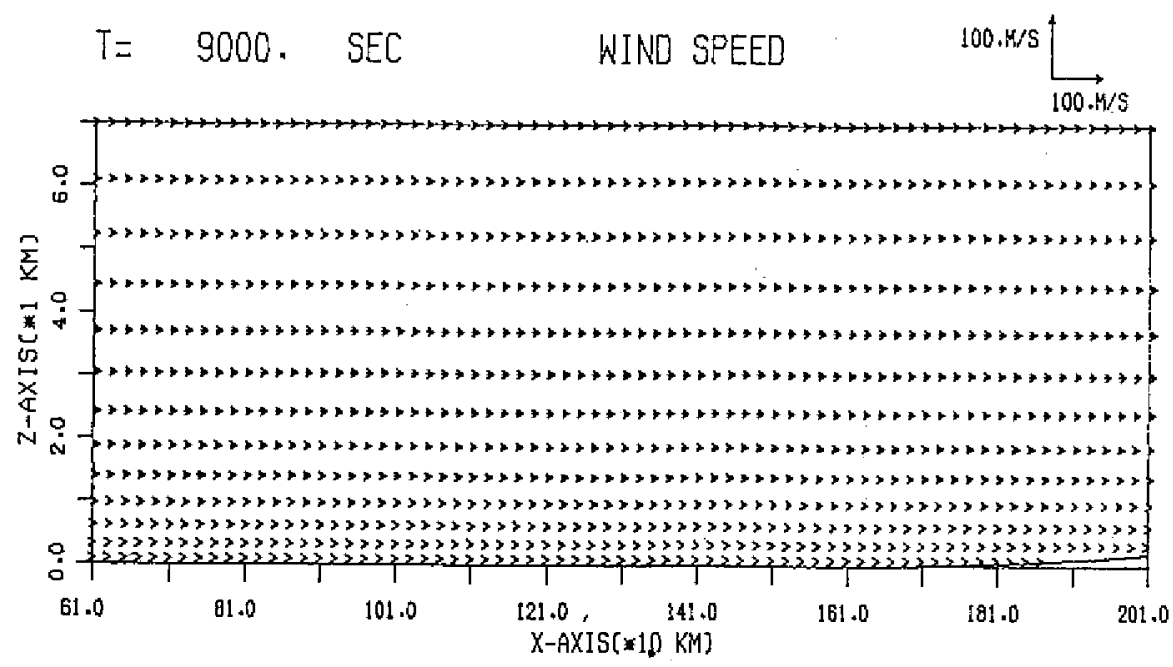

$F i g .3$. The flow pattern after the initialization in run $A$ at $9000 \mathrm{~s}$. The simulation result is shown in a portion of the domain on every other point horizontally.

At $9000 s\left(2 \frac{1}{2}\right.$ hours) convection was initiated by cooling a region in the low levels $8.0 \mathrm{~km}$ long by $3.8 \mathrm{~km}$ thick. This technique was applied to the region located from 60 to $68 \mathrm{~km}$ away from the left side of the model boundary at a 
cooling rate of $0.007 \mathrm{~K} \mathrm{~s}^{-1}$ for 10 minutes. Beside that, $10 \mathrm{~g} \mathrm{~kg}^{-1}$ of water vapor was added in that region for 10 minutes to accelerate the formation of the precipitation cloud. If the cooling rate was reduced or the magnitude of the extra supply of water vapor was decreased, no precipitation cloud could last longer during our simulation.
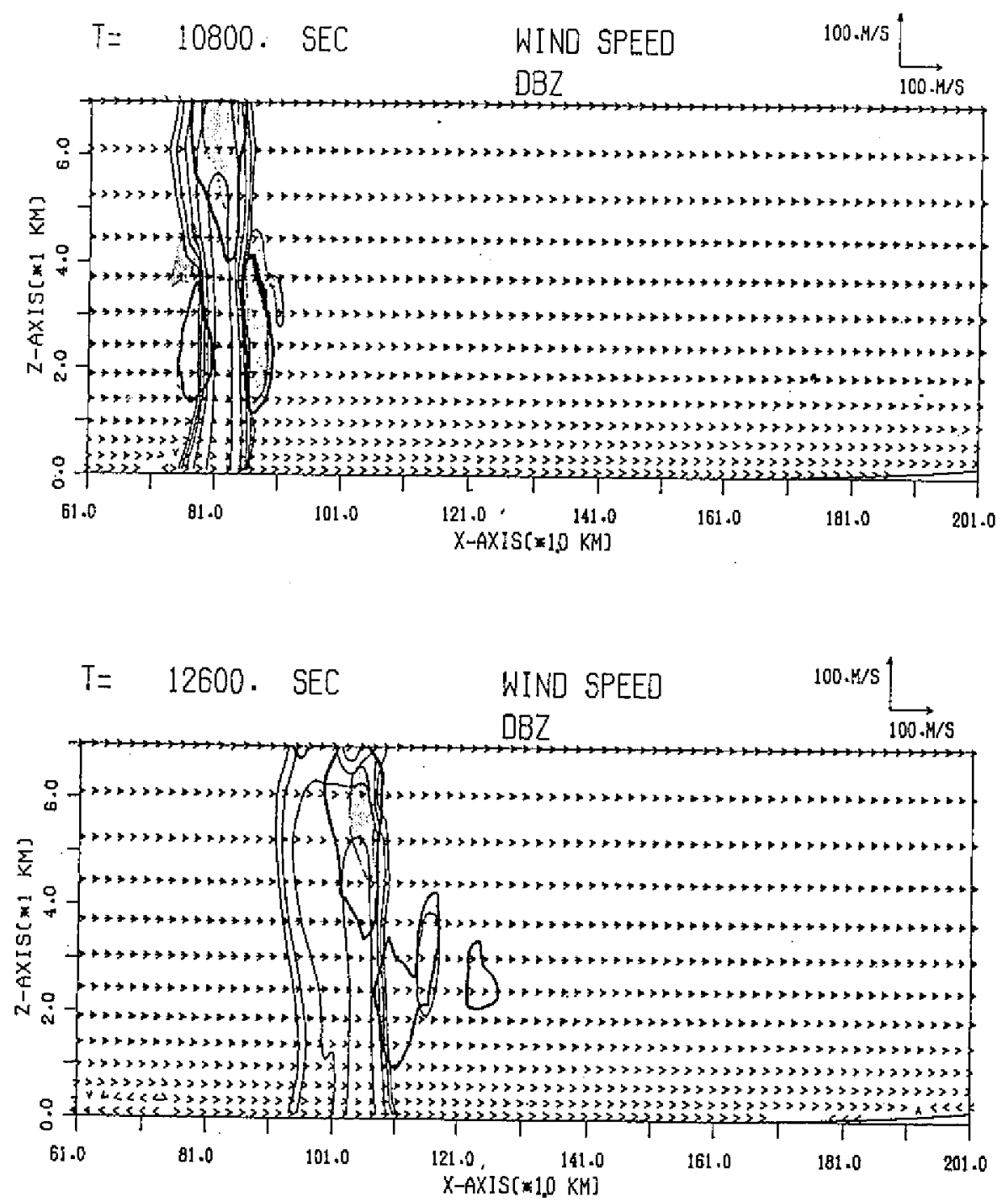

Fig. 4. Model estimated radar reflectivity (dBZ) presented at 30 min intervals from $10800 s$ to $30600 s$ in run $A$ on every other point horizontally. The contour intervals are $10 \mathrm{dBZ}$. Wind vector is superimposed on the reflectivity. The shaded area encloses the vertical velocity greater than $2 \mathrm{~ms}^{-1}$. The heavy solid line represents $0.1 \mathrm{~g} \mathrm{~kg}^{-1}$ the mixing ratio of cloud water. 


\section{SIMULATION RESULTS}

There are three experiments in this study namely, run A, B, C. The terrain features of the three runs are shown in Fig. 1. The mountain top for run $A$ and $\mathrm{B}$ is $1 \mathrm{~km}$ but $2 \mathrm{~km}$ for run $\mathrm{C}$. The difference between run $\mathrm{A}$ and run $\mathrm{B}$ is that the width of the domain is $300 \mathrm{~km}$ for run $\mathrm{B}$ but $360 \mathrm{~km}$ for A. Since the cooling region that triggers the initial convection is $60 \mathrm{~km}$ away from the left side of the domain for run $\mathrm{A}, \mathrm{B}$, and $\mathrm{C}$, the initial convection formed in run $\mathrm{B}$ was much closer to the mountain.

\section{a. Run $A$}

In order to study topographical effects on a squall line we examined in this experiment the evolution of a model squall line propagating towards the mountains. After initiation of the wind field the flow pattern at $9000 s$ is shown in Fig. 3 where westerly wind was observed. The simulation results were only presented for a portion of domain in the horizontal and vertical directions, respectively. This implies that simulation results above $7 \mathrm{~km}$ in the absorbing layer are not shown here. If no significiantly upward motion existed in the model, no squall line could occur. Therefore we had to artificially supply upward motion to form a squall line. This upward motion would come from some artificial cooling in the low levels. After the artificial cooling and moistening effect applied to the region between $x=61$ to $68 \mathrm{~km}$ in the next 10 min from $9000 \mathrm{~s}$ a model sqall line formed near $81 \mathrm{~km}$ at $10800 \mathrm{~s}$ (Fig. 4). This position was about $160 \mathrm{~km}$ away from the mountain peak (at $x=241 \mathrm{~km}$ ). The squall line formed near the leading edge of the cooling air moving toward the the mountain. The intensity of the squall line was represented by the radar reflectivity (dBZ) which was proportional to the mixing ratio of rain (Fovell and Ogura, 1988). The outlines of upward motion $\left(>2 \mathrm{~m} \mathrm{~s}^{-1}\right)$ and cloud $\left(>0.1 \mathrm{~g} \mathrm{~kg}^{-1}\right)$ are superimposed on the dBZ contours. While the model squall line was propagating eastward new convection continually formed on the forward side of the squall line (east side) and the older convection decayed at the back side. The gradient of $\mathrm{dBZ}$ was tight near the front edge of the squall line which implied that the convection was strong there. The upward motion was over $2 \mathrm{~m} \mathrm{~s}^{-1}$ at the forward side of the squall line as shown in the figures before $19800 \mathrm{~s}$. Before $19800 \mathrm{~s}$ the model squall line roughly maintained a speed of $14 \mathrm{~m} \mathrm{~s}^{-1}$ towards the east with the maximum intensity over $50 \mathrm{dBZ}$ in the plain area. The magnitude of the westerly wind was reduced on the back of the squall line while it was increased on the leading edge. After $19800 \mathrm{~s}$ the squall line climbed the mountain to where the altitude was over $300 \mathrm{~m}$. Less moisture content was observed in Fig. 2 at the higher terrain. The squall line slowed 

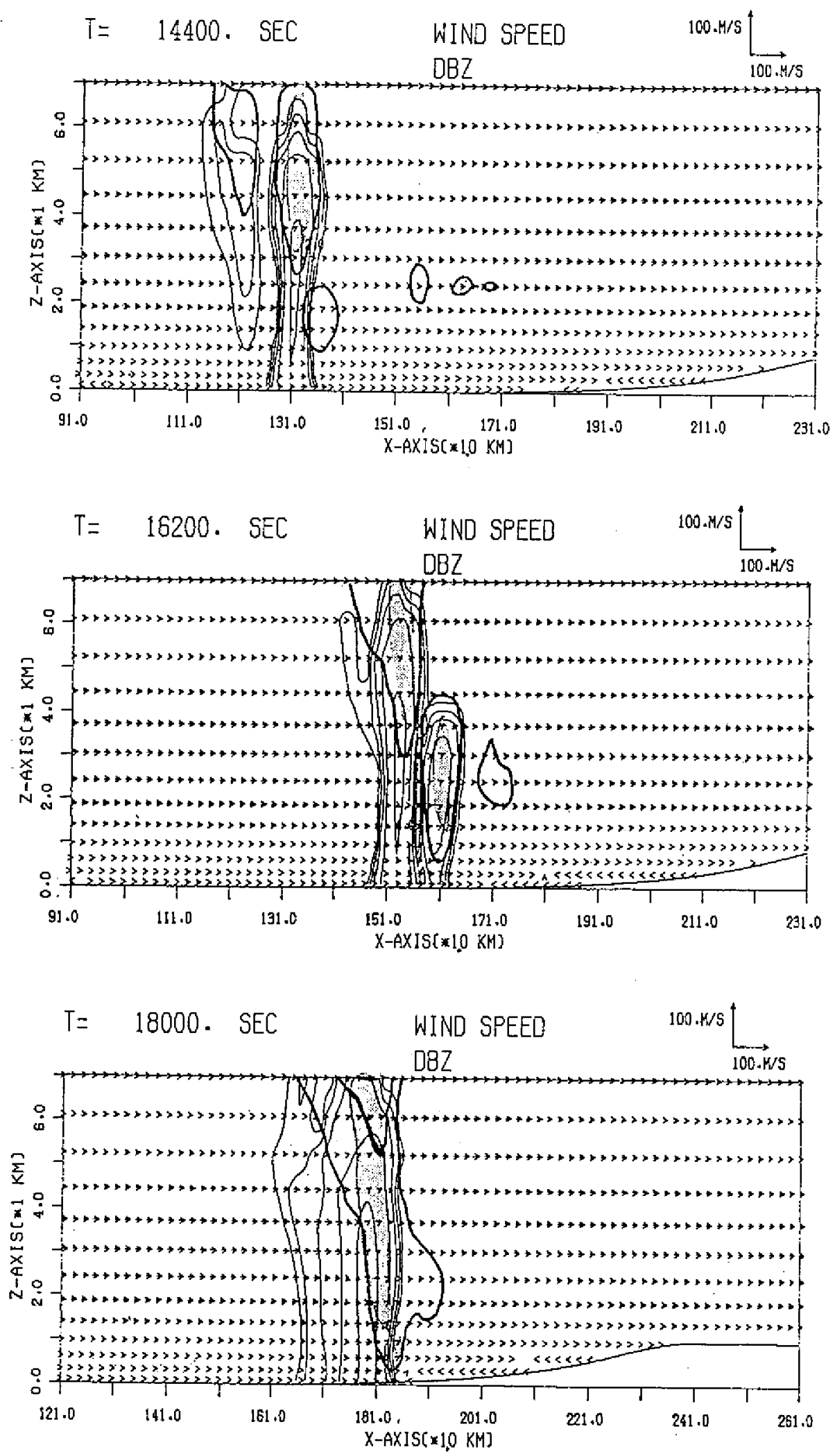

Fig. 4. (Continued) 

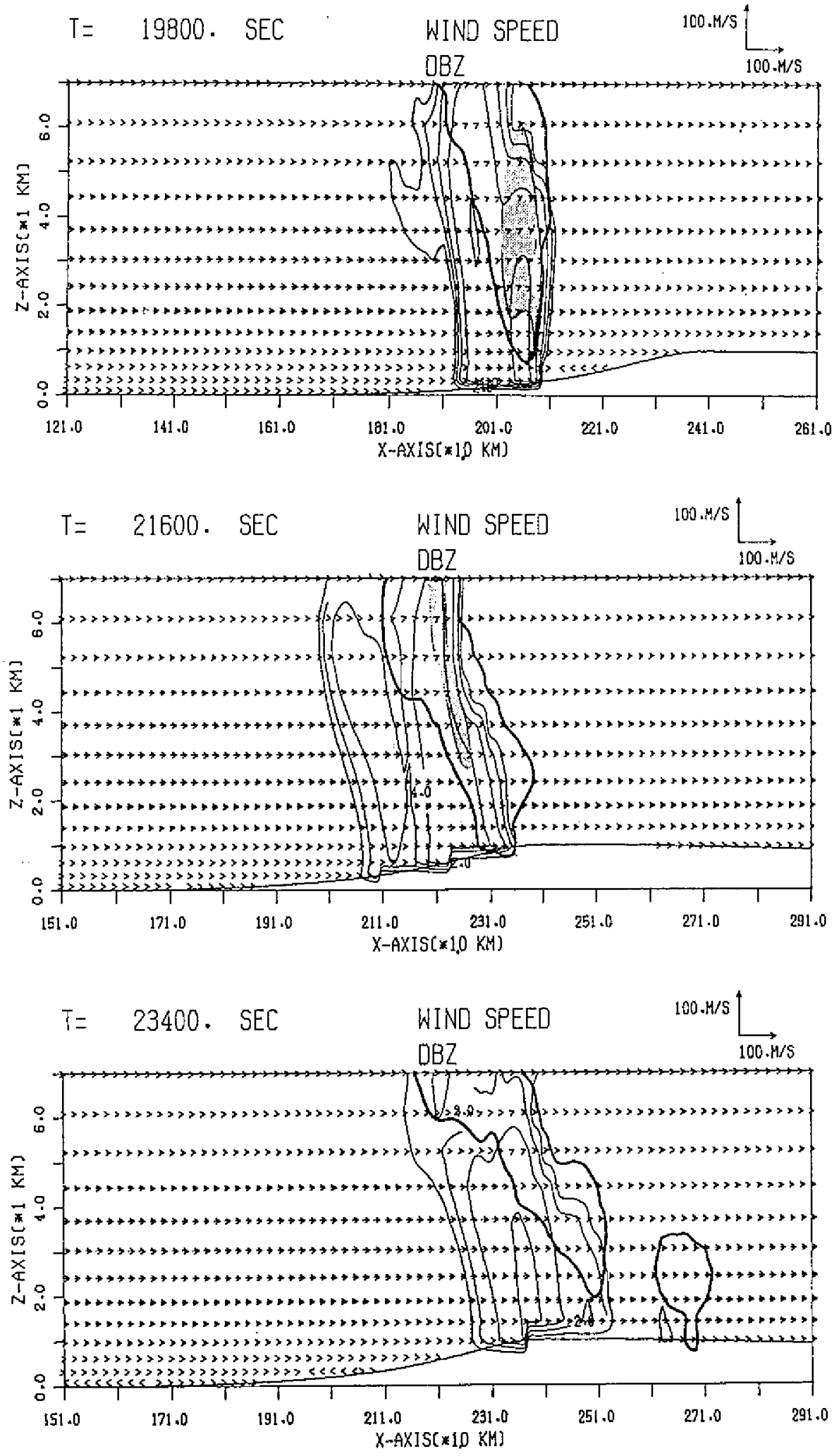

Fig. 4. (Continued) 


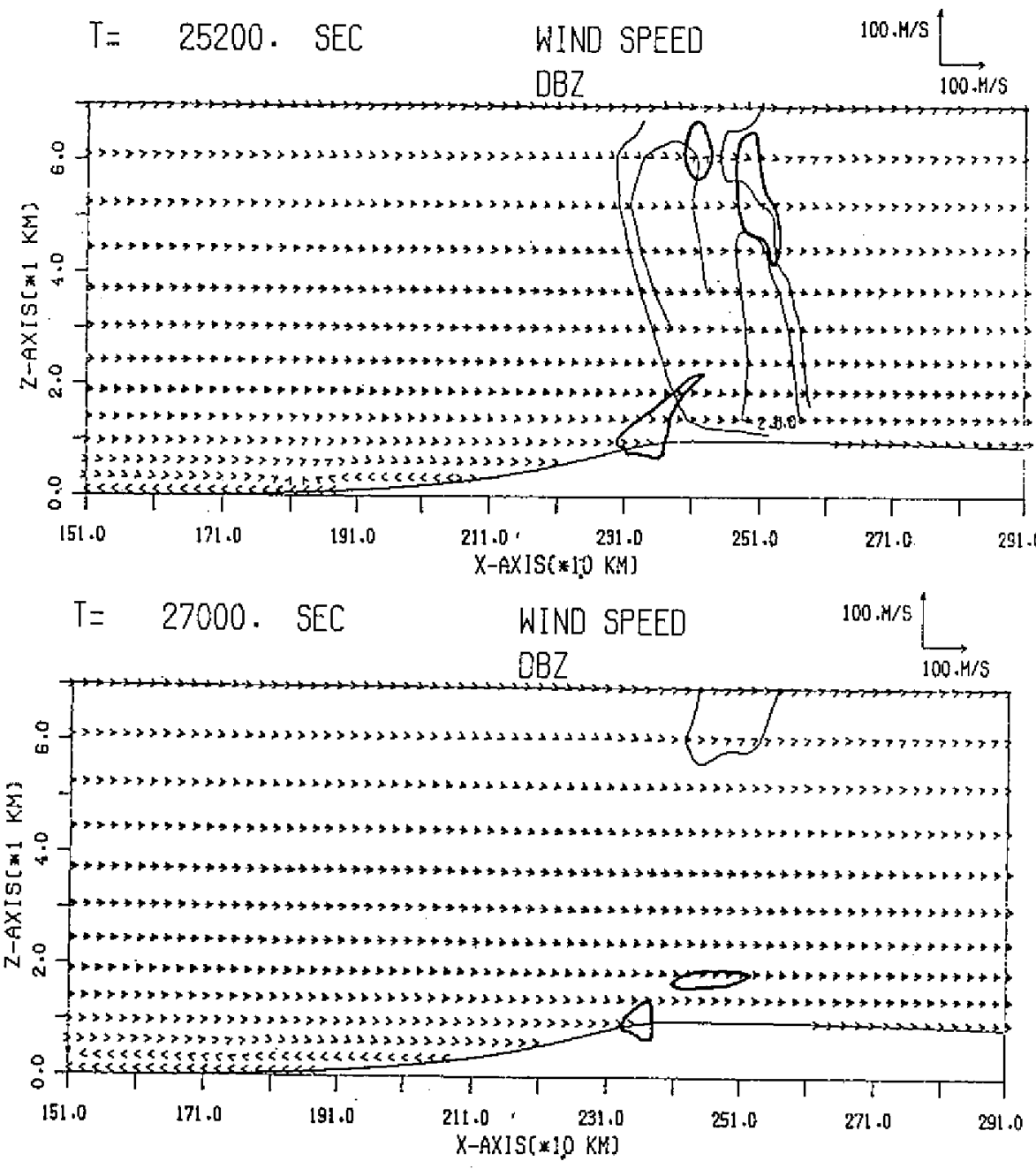

Fig. 4. (Continued)

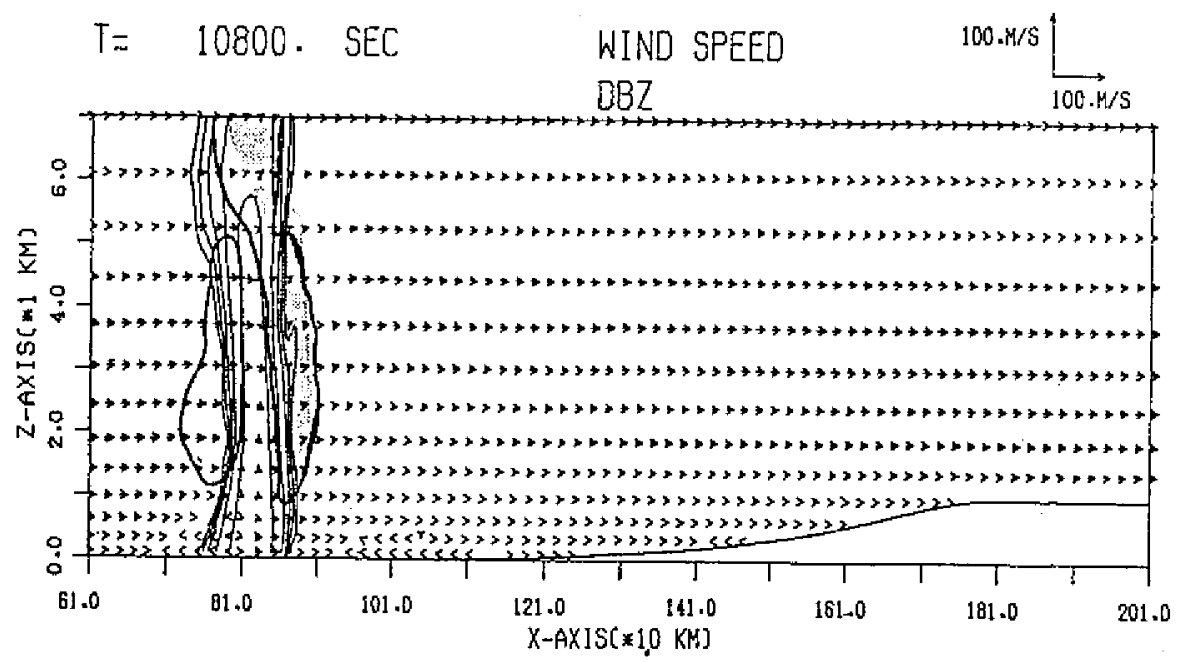

Fig. 5. Same as in Fig. 4 but for run B at some selected time. 

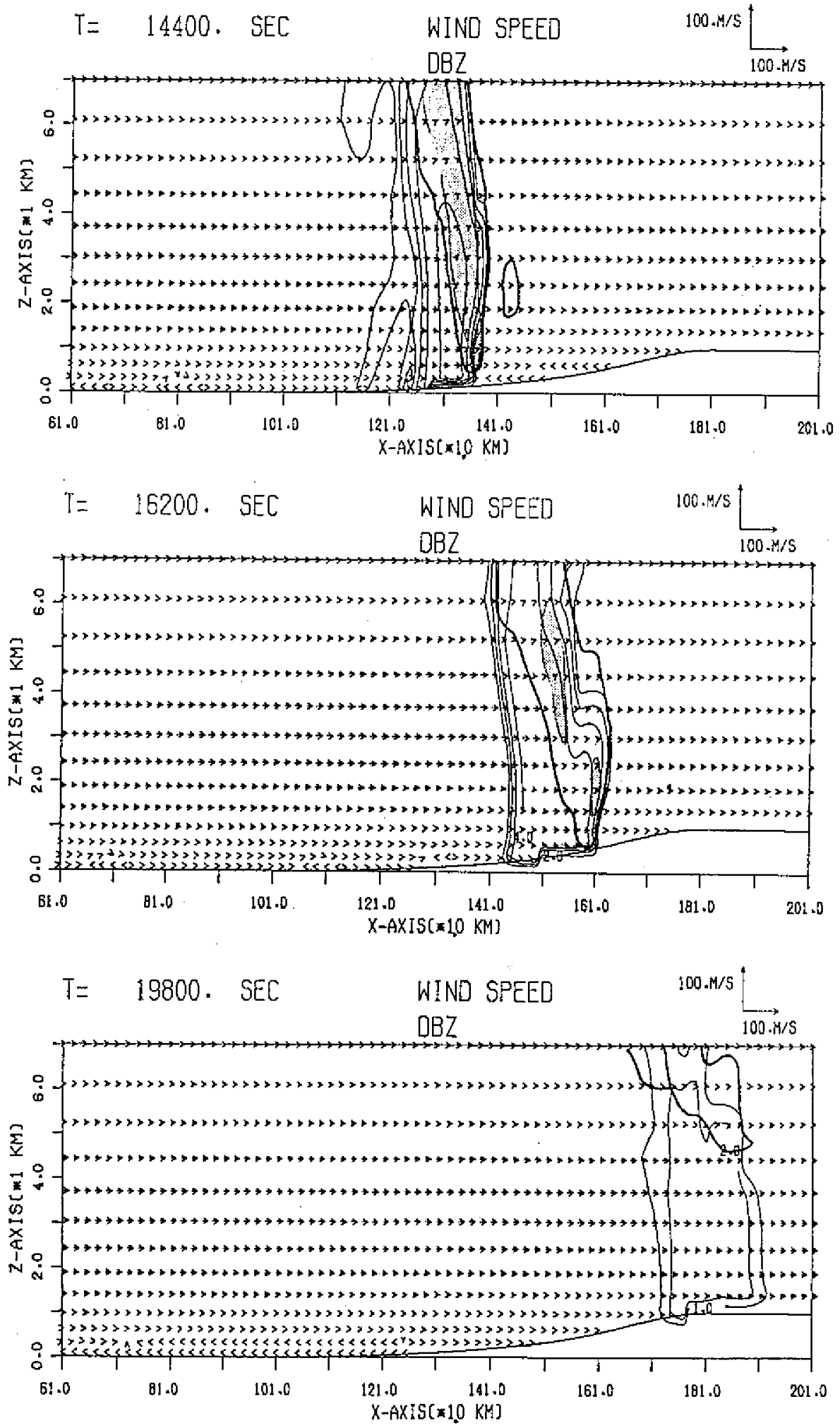

Fig. 5. (Continued) 
down and its intensity began decreasing as the new convection on the front side of the squall line weakened as shown in the $w$ pattern. The magnitude of the upward motion was smaller than $2 \mathrm{~m} \mathrm{~s}^{-1}$ after $21600 \mathrm{~s}$. This was due to the fact that the moisture flown into the squall line was less in the mountains than that in the plain area. Less moisture supply resulted in less condensation which caused a decrease of the upward motion. As the squall line came over the top of mountain (after $23400 s$ ) it shrank very quickly and dissipated. However some low level clouds could still exist in the mountainous area.

\section{b. Run $B$}

What would happen to a squall line if it formed much closer to a mountain? Run B was set to investigate this phenomenon. Similar initiating procedures to those in run A were used but the coolng and moistening effect to initiate convection at $9000 s$ was applied to an area much closer to the mountain. Thus a squall line formed much closer to the mountainous area. At $10800 \mathrm{~s}$ a squall line (Fig. 4) occurred near $81 \mathrm{~km}$ which was about $100 \mathrm{~km}$ away from the top of mountain ( at $x=181 \mathrm{~km}$ ). As before this squall line occurred at the front edge of the cooling air moving toward the mountain. Before $14400 \mathrm{~s}$ the maximum intensity of the squall line was over $50 \mathrm{dBZ}$ in the plain area. New convection continually formed on the front edge of the squall line to maintain the intensity of the squall line. The magnitude of the upward motion was over $2 \mathrm{~m} \mathrm{~s}^{-1}$. After $14400 \mathrm{~s}$ this squall line climbed a mountain with an altitude of over $300 \mathrm{~m}$. The intensity of the squall decreased and eventually it dissipated after $19800 \mathrm{~s}$. In the previous experiment the intensity of the squall line was still over $50 \mathrm{dBZ}$ at $19800 \mathrm{~s}$ while in this run the intensity was less than $20 \mathrm{dBZ}$. Both experiments indicated that mountains could inhibit the development of the model squall line when it was in the mountain area no matter how far away from mountain the squall line formed.

\section{c. Run $C$}

This experiment is designed to study the impact of terrain on a squall line moving toward a mountain if its peak is higher ( $2 \mathrm{~km}$ in this run). A similar initiation technique to that used in run $\mathrm{A}$ is applied for this experiment. At $10800 \mathrm{~s}$ a squall line was found near $81 \mathrm{~km}$ about $160 \mathrm{~km}$ away from the top of mountain ( Fig. 5). Since new convection continually formed on the front edge of the squall line, it could keep its outskirts and its maximum intensity over 50 $\mathrm{dBZ}$ untill $18000 s$ as the squall line moved eastward. Since the lifting due to the mountain was stronger in this run than that in run $A$, the intensity of the squall line was a little higher in run $\mathrm{C}$ before $18000 \mathrm{~s}$ as shown in the $50 \mathrm{dBZ}$ 
$T=$ 10800. SEC

WIND SPEED

$100 . \mathrm{H} / \mathrm{S}$

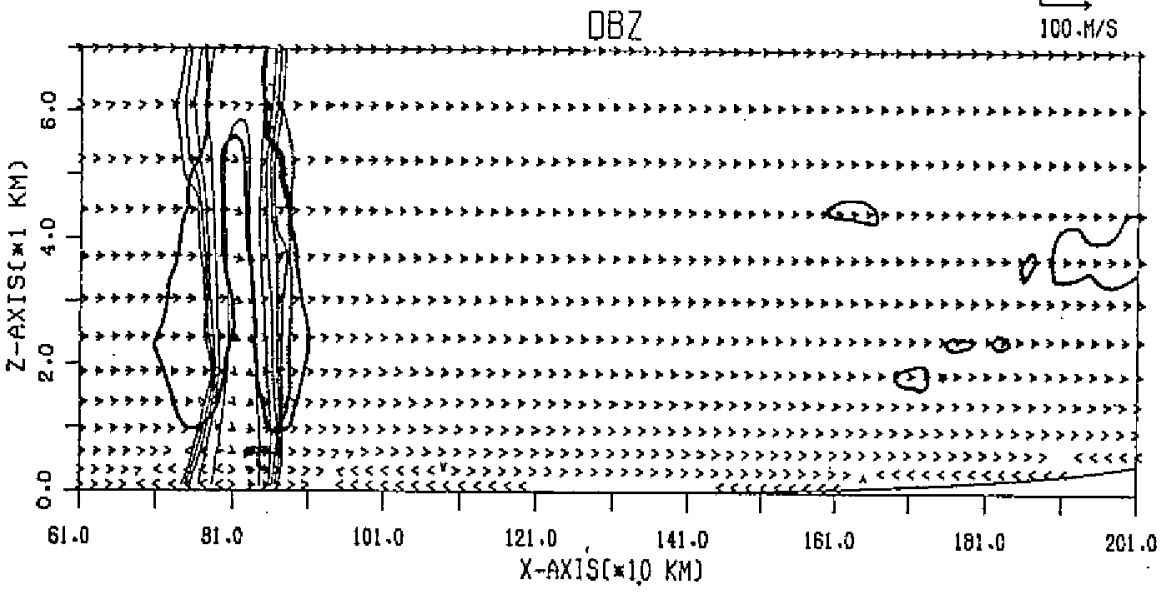

$T=14400$. SEC

WIND SPEED

$\mathrm{DBZ}$

$100 \cdot, / 5$

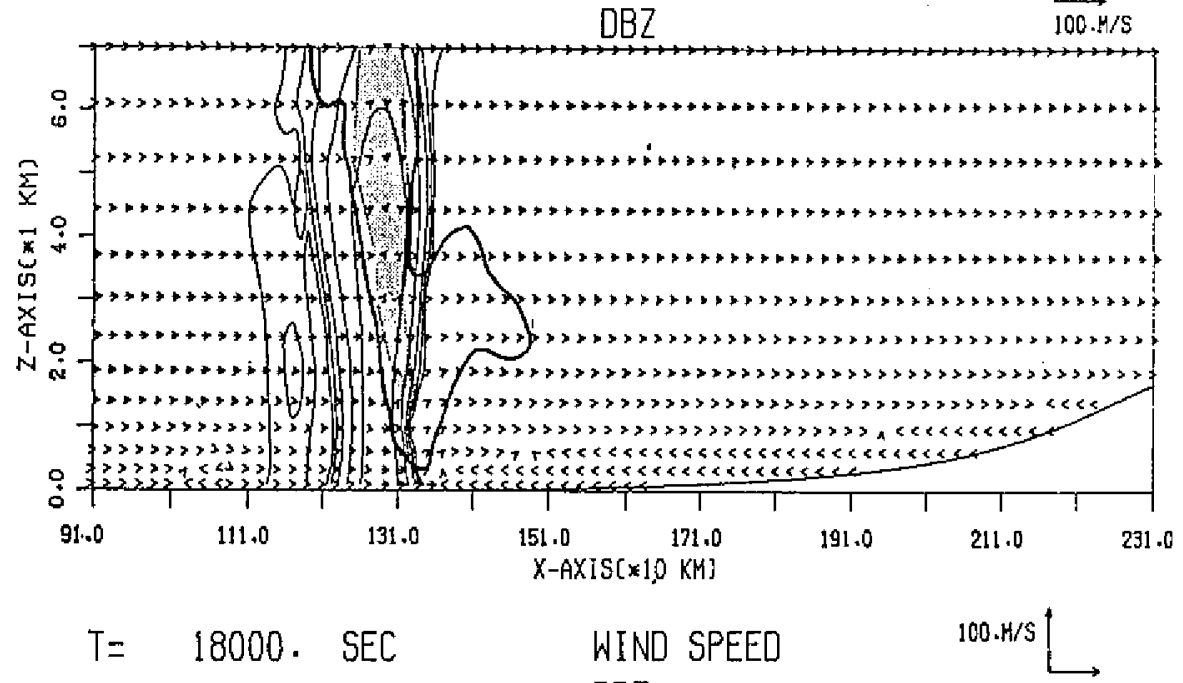

$\mathrm{DBZ}$

$100.4 / 5$

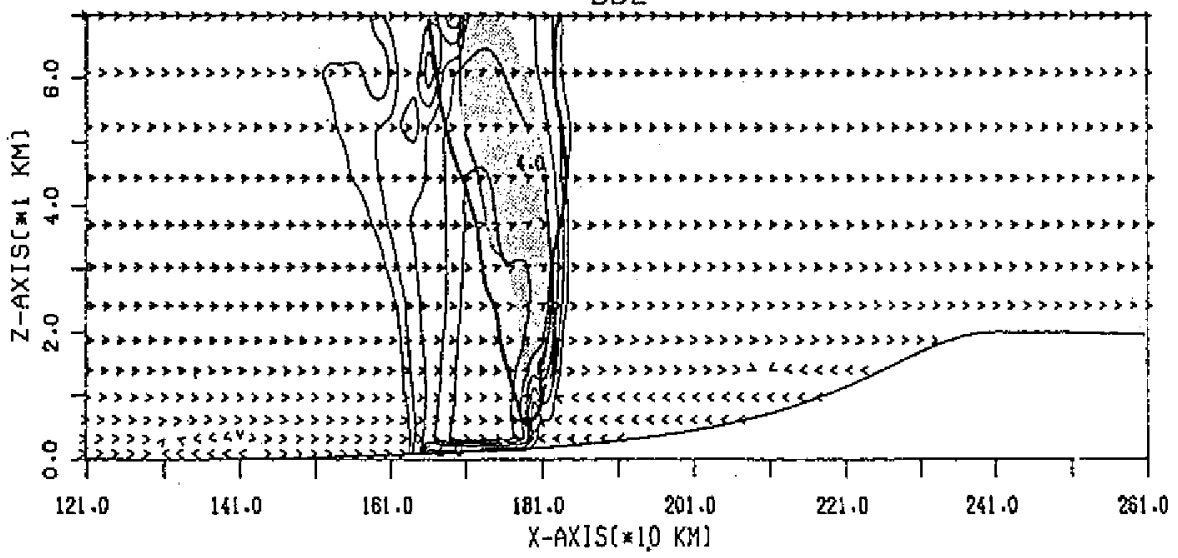

Fig. 6. Same as in Fig. 4 but for run $\mathrm{C}$ at some selected time. 

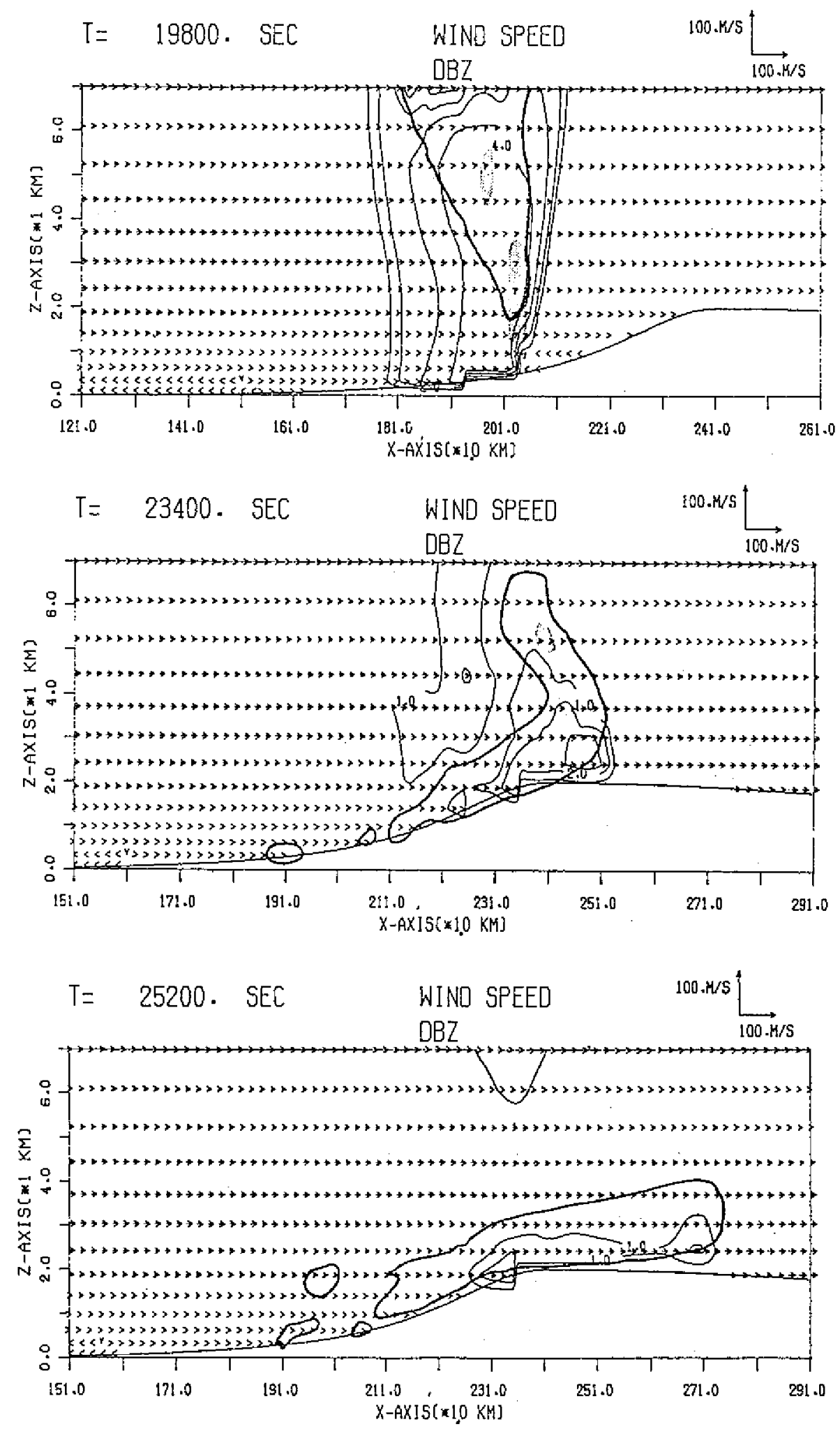

Fig. 6. (Continued) 
contour and the upward motion (Figs. 4 and 6). After that the intensity of the squall line began decreasing as it climbed upward above the $300 \mathrm{~m}$ height. The magnitude of the upward motion and the radar reflectivity both decreased. As this precipitation system came over the top of mountain precipitation only remained near the ground. The model squall line began to weaken earlier (after $18000 \mathrm{~s}$ ) than that in run A (after $19800 \mathrm{~s}$ ) since it encountered higher mountains in run $\mathrm{C}$. The higher the altitude the less moisture supplied to the squall line in the model.

\section{CONCLUSION}

A two-dimensional terrain following coordinated cloud model was used to study the geographical effect on a model squall line moving toward mountains. The results indicated that a squall line can maintain itself through continual formation of new convection at the front edge of the squall line in a plain area but as the squall line encountered mountains it slowed down and began weakening as a result of the weakness of the new convection. The decrease in intensity was due to less moisture flown into the squall line at the higher altitudes. If the mountain peak was higher, the terrain effects on the inhibition of the development of the squall line was more evident.

Acknowledgments. This research was supported by the National Science Council under grant NSC79-0202-M008-27. I wish to thank Institute of Atmospheric Physics, National Central University for the use of its computer facilities.

\section{APPENDIX}

The momentum, thermodynamic, continuity equations and microphysical processes used in this study for the terrain following coordinated system are

$$
\begin{gathered}
\frac{\partial u}{\partial t}+u \frac{\partial u}{\partial x}+(G u+H w) \frac{\partial w}{\partial \eta}+C_{p} \bar{\theta}_{v}\left(\frac{\partial \bar{u}}{\partial x}+G \frac{\partial \bar{u}}{\partial \eta}\right)=D_{u} \\
\frac{\partial w}{\partial t}+u \frac{\partial w}{\partial x}+(G u+H w) \frac{\partial w}{\partial \eta}+C_{p} \frac{\tilde{\theta}_{v} H \partial \pi}{\partial \eta} \\
=g\left[\frac{\theta}{\bar{\theta}}-1+0.61\left(q_{v}-\bar{q}_{v}\right)-q_{c}-q_{r}\right]+D_{w} \\
\frac{\partial \pi}{\partial t}+u \frac{\partial \pi}{\partial x}+(G u+H w) \frac{\partial}{\partial \eta}(\bar{\pi}+\pi)=0
\end{gathered}
$$




$$
\begin{gathered}
\frac{\partial \theta}{\partial t}+u \frac{\partial \theta}{\partial x}+(G u+H w) \frac{\partial \theta}{\partial \eta}=M_{\theta}+D_{\theta} \\
\frac{\partial q_{v}}{\partial t}+u \frac{\partial q_{v}}{\partial x}+(G u+H w) \frac{\partial q_{v}}{\partial \eta}=M_{q_{v}}+D_{q_{v}} \\
\frac{\partial q_{c}}{\partial t}+u \frac{\partial q_{c}}{\partial x}+(G u+H w) \frac{\partial q_{c}}{\partial \eta}=M_{q_{c}}+D_{q_{c}} \\
\frac{\partial q_{r}}{\partial t}+u \frac{\partial q_{r}}{\partial x}+(G u+H w) \frac{\partial q_{r}}{\partial \eta}=M_{q_{r}}+D_{q_{r}}
\end{gathered}
$$

where

$$
\eta=\frac{z_{t}\left(z-z_{s}\right)}{\left(z_{t}-z_{s}\right)}
$$

$z_{t}$ is the top of domain $(18.2 \mathrm{~km})$.

$$
z_{s}(x)=\frac{h \alpha^{2}}{\left(x^{2}+a^{2}\right)}
$$

$h$ is the mountain peak and $a$ is $2400 m$ or $144000 m$ depending on the $x$ in the west or the east side of the mountain peak, respectively.

$$
\begin{gathered}
G=\frac{\partial \eta}{\partial x} \\
H=\frac{\partial \eta}{\partial z} \\
\theta_{v}=\theta\left(1+0.61 q_{v}\right) \\
\pi=\left(\frac{p}{p_{0}}\right)^{\frac{R}{C_{p}}}
\end{gathered}
$$

$D_{u}, D_{w}, D_{\theta}, D_{q_{v}}, D_{q_{\mathrm{c}}}$ and $D_{q_{r}}$ represent the subgrid scale mixing for $u, w$, potential temperature $\theta$, mixing ratio of water vapor $q_{v}$, mixing ratio of cloud water $q_{c}$, and mixing ratio of rain water $q_{r}$. They all are taken from Lilly (1962) and the mixing coefficient was dependent on the relative strengths of stratification and shear. $M_{\theta}, M_{q_{v}}, M_{q_{c}}$, and $M_{q_{r}}$ denote the microphysical terms associated with warm rain processes for potential temperature, water vapor, cloud water and rain, respectively. (Klemp and Wilhelmson). Bars over individual variables refers to the initial undisturbed state. 


\section{REFERENCES}

Cunning, J. B.,1988: Taiwan Area Mesoscale Experiment: Daily operations summary. NCAR Technical Note, NCAR-TN-305+STR, 360pp.

Durrain, D. R., and J. B. Klemp, 1982: The effect of moisture on trapped mountain lee waves. J. Atmos. Sci., 39, 2490-2506.

Fovell, R. G., and Y. Ogura, 1988: Numerical simulation of a midlatitude squall line in two dimensions. J. Atmos. Sci., 45, 3846-3879.

Kessler, E., 1969: On the distribution and continuity of water substance in atmospheric circulation. Met. Mon. Amer. Met. Soc., 10, 84pp.

Klemp, J., and R. Wilhelmson, 1978: The simulation of three-dimensional convective storm dynamics. J. Atmos. Sci, 35, 1070-1096.

Lilly, D. K., 1962: On the numerical simulation of buoyant convection. Tellus, 14, 148-172.

Simth, R. B., 1979: The influence of mountains on the atmosphere. Advances in Geophysics, 21, 87-230.

Yoshizaki M., and Y. Ogura, 1988: Two- and three-dimensional modeling studies of the Big Thompson storm. J. Atmos. Sci., 45, 3700-3722. 


\title{
地形對颮線影響的數值研究
}

\author{
陳景森 \\ 國立中央大學大氣物理硏究所
}

摘 要

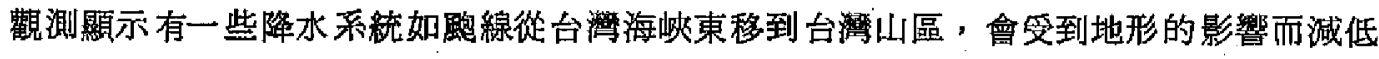
其強度, 然後消散。顯然地形效雄相當重要, 吾人利用一有地形座標的雲雨模式來探討地形 對㶡岛線的影響, 在模式內, 山頂假設 1 或 2 公里高, 模式中的咆線在平原產生後, 能繼續發

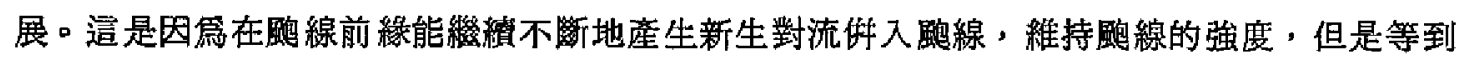
良線進入山區, 移動速度減慢, 而且強度減嫋, 減弱的原因, 是由於新生對流燓弱, 而新生 對流的強度衰退, 是由於在山區流入跑線的水泛減少。另外模擬結果顯示山的高度愈高, 抑 制跑線發展的效應也永大。 